\title{
O princípio da separação de línguas no teletandem: o que as teorias propõem e como ele funciona na prática
}

DOI: http://dx.doi.org/10.21165/el.v49i3.2458

\author{
Fabiana Picoli ${ }^{1}$ \\ Ana Cristina Biondo Salomão
}

\section{Resumo}

Baseando-se na modalidade de aprendizagem em tandem, Telles e Vassallo (2006) propuseram o Teletandem, que ocorre por meio de ferramentas digitais na internet com foco na comunicação oral. O princípio da separação de línguas (TELLES; VASSALLO, 2006) é denominado, neste estudo, princípio da igualdade. Nesse artigo, buscamos refletir sobre os fatores que envolvem o seguimento desse princípio durante a realização do teletandem a partir de discussões teóricas sobre suas diferentes denominações e conceituações, assim como por meio da análise de dados empíricos de interações entre três pares de participantes. Nossos resultados demonstram a necessidade de renomeação desse princípio no teletandem e uma reconceitualização que reconheça as características do uso de duas línguas nesse contexto de acordo com as necessidades, objetivos e intenções dos falantes.

Palavras-chave: teletandem; princípio da separação de línguas; alternância de códigos.

\footnotetext{
1 Universidade Estadual Paulista "Júlio de Mesquita Filho" (UNESP), Araraquara, São Paulo, Brasil; fapicol@gmail.com; https://orcid.org/0000-0001-9601-5765

2 Universidade Estadual Paulista "Júlio de Mesquita Filho" (UNESP), Araraquara, São Paulo, Brasil; ana.salomao@unesp.br; https://orcid.org/0000-0002-1531-8551
} 


\title{
Separation of languages on teletandem: what theories propose and how it works in practice
}

\begin{abstract}
Based on the tandem learning modality, Telles and Vassallo (2006) proposed Teletandem, which occurs through digital internet tools focusing on oral communication. The principle of separation of languages (TELLES; VASSALLO, 2006) is named in this study as the principle of equality. In this article, we seek to reflect on the factors that involve the use of this principle during teletandem sessions through theoretical discussions about their different denominations and conceptualizations, as well as through the analysis of empirical data of interactions between three pairs of participants. Our results demonstrate the need for the renaming of this principle in teletandem and for a reconceptualization that recognizes the characteristics of using two languages in this context according to the needs, objectives and intentions of speakers.
\end{abstract}

Keywords: teletandem; principle of separation of languages; code-switching.

\section{Introdução}

A prática de línguas estrangeiras oportunizada pelo Teletandem (TELLES; VASSALLO, 2006; TELLES, 2009) tem proporcionado o contato entre aprendizes de diferentes línguas para a aprendizagem colaborativa, por meio de aplicativos de comunicação síncrona na internet. Segundo Costa, Salomão e Zakir (2018, p. 14), nesse contexto, denominase interação "o momento em que os parceiros ajudam um ao outro no processo de aprendizagem", por meio de uma conversa que ultrapassa os limites de simples bate-papo uma vez que os participantes devem atentar-se não somente ao conteúdo, mas também à forma como a língua é usada. As autoras explicam que, no caso da modalidade de teletandem institucional, em que a maioria das sessões é feita em grupos no laboratório de idiomas das universidades, a duração é geralmente de 50 a 75 minutos.

O teletandem, segundo Vassalo e Telles (2006), é alicerçado sobre três princípios: a autonomia, a reciprocidade e o uso separado das línguas, o qual é denominado pelos autores como princípio da separação de línguas. Uma vez que nosso foco é este último princípio, nos dedicaremos a ele com mais profundidade no decorrer do artigo a fim de apresentar uma análise de interações entre três pares de aprendizes, considerando o tempo de prática para as línguas-alvo ${ }^{3}$ bem como um fenômeno decorrente do bilinguismo, denominado code-switching ou alternância de códigos. Assim, nossa proposta é primeiramente discutir o que propõem as teorias sobre o princípio da separação de línguas, assim como demonstrar por meio de dados empíricos como ele funciona nas

3 Neste artigo, o termo "línguas-alvo" refere-se a português e inglês. 
interações, do ponto de vista do tempo dedicado à prática de cada língua-alvo e como as alternâncias de códigos podem influenciar o seguimento desse princípio.

Acreditamos que nossa discussão poderá trazer à tona reflexões que perpassam teoria e prática telecolaborativas, trazendo questionamentos acerca do funcionamento do princípio de separação de línguas nas interações de teletandem, como também uma proposta para possível renomeação ou reformulação de tal conceito à luz dos resultados apresentados.

\section{Teletandem: princípios teóricos}

Essa modalidade de aprendizagem de línguas foi embasada na prática de línguas estrangeiras em tandem, que se popularizou nos anos 1970, na Espanha (VASSALLO; TELLES, 2006), cujo termo faz referência a uma bicicleta de dois lugares que precisa ser guiada colaborativamente. Inicialmente, o tandem era realizado face a face, ou seja, os parceiros se encontravam em um mesmo espaço físico previamente combinado para praticarem a língua-alvo um do outro por meio da conversação. O tempo para a prática de ambas as línguas era dividido de maneira igualitária, consequentemente, ao mudar o idioma, os papéis se invertiam, ou seja, aquele que anteriormente aprendia a língua do parceiro passava a ajudá-lo a aprender sua língua materna ou de proficiência (BENEDETTI, 2009).

Com o passar do tempo, no início dos anos 1990, a aprendizagem de LE na modalidade tandem passou por avanços significativos proporcionados pelas Tecnologias da Informação e Comunicação (TICs), principalmente pela internet, fazendo com que o tandem evoluísse para uma modalidade realizada a distância, intitulada e-tandem ou tandem eletrônico (BENEDETTI, 2009), que possibilitava a prática de línguas estrangeiras através da comunicação assíncrona (carta, e-mail) ou síncrona (telefone, chat).

Nesse novo cenário, surgiu em março de 2006, nos campi da Universidade Estadual Paulista "Júlio de Mesquita Filho" (UNESP) de Assis e de São José do Rio Preto/SP, o projeto "Teletandem Brasil: línguas estrangeiras para todos", idealizado por Telles (2009), sendo uma modalidade de tandem virtual que utilizava o aplicativo do Windows Live Messenger (aplicativo de mensagens instantâneas) e a webcam a fim de possibilitar que dois aprendizes distantes geograficamente interagissem sincronicamente por meio de videoconferência. De acordo com Benedetti (2009), comparando o teletandem com o modelo de tandem eletrônico que o antecedeu, o modelo de Telles e Vassallo (2006) era inovador, pois não só proporcionava comunicação oral simultânea entre os parceiros através de uma webcam, como também unia ferramentas para a prática da escrita da língua (chat) como nas outras formas de tandem. 
Como já mencionado, a prática de línguas estrangeiras por meio do tandem e do teletandem envolve o seguimento de três princípios teóricos. O princípio da autonomia no tandem, conforme Brammerts (2002), indica que, nesse contexto, o aprendiz deve ter a responsabilidade de estabelecer seus objetivos pessoais bem como a forma de atingi-los, em colaboração com um parceiro que é simultaneamente falante nativo ou proficiente da sua língua-alvo e aprendiz de sua língua materna. Ainda conforme o teórico, a autonomia demanda que a parceria estabeleça acordos relacionados ao trabalho em comum, por exemplo, temas para comunicação, formas de correção e feedback etc.

Vassallo e Telles (2006, p. 88-89, tradução nossa4) descrevem a autonomia no teletandem como "liberdade para negociar níveis de responsabilidade e reciprocidade com o parceiro", pois partindo desse princípio é possível que ambos compartilhem tarefas, podendo organizar um esquema de estudo de acordo com suas necessidades e organizar o ritmo de aprendizagem. Desse modo, o princípio da autonomia está intimamente ligado ao da reciprocidade, isto é, um não é visto sem o outro.

Brammerts (2002) define a reciprocidade no tandem como mesma disponibilidade e capacidade para ajudar um parceiro. No seu papel de "ajudante", um bom parceiro de tandem "reconhece a autonomia do outro e está disposto a dar-Ihe apoio, mesmo quando a forma de aprender é diferente da sua". Segundo o autor, para a relação tandem é preciso aplicar a regra fundamental de qualquer parceria, ou seja, os dois parceiros precisam tirar proveito da situação de aprendizagem, de preferência, na mesma medida. Por essa razão, Brammerts (2002) defende a importância de se dividir o tempo de interação em cada uma das duas línguas de maneira igualitária para que ambos os parceiros se beneficiem igualmente na prática de sua língua-alvo, comentando que, ao pensar sobre a reciprocidade no tandem, "provou ser benéfico dar maior relevância ao componente temporal (metade do tempo para cada um dos parceiros)" (BRAMMERTS, 2002, p. 20). Em consonância com Brammerts (2002), Little (2002, p. 31) declara que o princípio da reciprocidade, nas parcerias de tandem presencial, é um encontro que necessita ser dividido em duas partes, "cada uma dedicada a uma língua".

No entanto, Salomão, Silva e Daniel (2009, p. 88) afırmam que a reciprocidade no teletandem "está relacionada à igualdade de uso das línguas, em termos de tempo", porém, compreendem que esse princípio não se limita apenas à questão temporal de uso das línguas-alvo, mas deve abranger questões mais amplas, por exemplo, o "compromisso com o ensino e a aprendizagem de seu parceiro" (SALOMÃO; SILVA; DANIEL, 2009, p. 88).

Sobre a reciprocidade no teletandem, Vassallo e Telles (2009, p. 88) declaram que esse princípio "oferece a liberdade de negociação entre os parceiros, bem como intenciona garantir o compromisso com o outro". Essa visão se aproxima da definição de Panichi

4 No original: "freedom to negotiate levels of responsibility and reciprocity with the partner". 
(2002), ao relatar que o princípio da reciprocidade é definido pela situação na qual os aprendizes devem trabalhar juntos no entendimento de que são mutuamente responsáveis pela aprendizagem um do outro, e, portanto, devem manter a coesão da parceria que crie um ambiente positivo de aprendizagem (PANICHI, 2002).

Em suma, Salomão, Silva e Daniel (2009), tal qual Vassallo e Telles (2009) e Panichi (2002), concordam que a reciprocidade no teletandem é um princípio segundo o qual ambos os aprendizes devem contribuir igualmente para a aprendizagem colaborativa, beneficiando-se da mesma maneira. Levando em consideração essas definições acerca do princípio da reciprocidade, concluímos que a igualdade de uso das línguas deve ser contemplada em outro princípio, nomeado por Telles e Vassallo (2009) como princípio da separação de línguas, o qual intitulamos "princípio da igualdade", que será explicitado a seguir.

O princípio da igualdade, denominado por Vassallo e Telles (2009, p. 23) de "separação de línguas", refere-se ao fato de que as sessões de teletandem são compostas de duas partes cronologicamente subsequentes ou realizadas em dois dias diferentes, nas quais cada parte deve ser realizada em somente uma língua, ou seja, elas não devem ser misturadas. O objetivo desse princípio, conforme os autores, é "incentivar e desafiar os aprendizes a falar a língua-alvo" (VASSALLO; TELLES, 2009, p. 23).

Em relação a esse princípio, Panichi (2002) adota o termo "igualdade", aludindo à igualdade de status, ou seja, ao garantir a mesma quantidade de tempo para a prática de ambas as línguas-alvo, asseguraríamos a igualdade de oportunidades para ambos os parceiros de teletandem. Em relação a esse princípio, a autora aponta para a necessidade de uma parceria tandem na qual ambas as línguas tenham o mesmo status e onde haja igual oportunidade para cada participante usar sua própria língua, não somente como fonte de insumo, mas também como fonte de explicações e compartilhamento sobre aspectos de sua cultura.

Little (2002, p. 31), ao tratar do uso de duas línguas distintas nas sessões de tandem, adota o termo "princípio do bilinguismo", definindo-o como "utilização de uma só língua, alternadamente, em cada encontro". Calvert (1999) denomina a igualdade de divisão de tempo de "princípio da responsabilidade". Apesar das divergências em relação às nomenclaturas para o princípio que rege o uso separado de duas línguas distintas na mesma quantidade de tempo, durante as sessões de tandem e teletandem, nosso ponto de vista se aproxima da definição de Panichi (2002), pois acreditamos ser, dentre as outras, a mais adequada para elucidar a utilização das línguas-alvo em proporções iguais pelos aprendizes. Entendemos que a expressão "igual oportunidade" ilustra melhor o esforço que ambos os parceiros devem fazer durante as sessões de forma a se beneficiarem na prática de sua LE. 
Entendemos também que a denominação "separação de línguas" se mostra problemática uma vez que, como asseverado por Little (2002, p. 33), o contexto de prática de línguas na modalidade tandem tem implicações inerentes ao conceito de bilinguismo, ou seja, a comunicação bilíngue se baseia num "confronto contrastivo entre língua materna e língua-alvo".

\section{O bilinguismo e a alternância de códigos}

As definições para o bilinguismo são vastas e, dependendo da concepção teórica, refletem diferentes pontos de vista. De acordo com García e Wei (2014), foi a visão saussureana de língua como sistema de estruturas independentes que permeou a visão de língua em estudos preliminares sobre bilinguismo. Desse modo, Weinreich (1953), por exemplo, considera o bilinguismo como um encontro de duas línguas; Haugen (1953) preconiza que o bilinguismo está atrelado ao repertório linguístico de um sujeito que tem conhecimento em mais de uma língua, ou seja, à sua capacidade de produzir enunciados significativos em uma LE ou L2. Mackey (1968) compreende o bilinguismo como uso alternado de duas ou mais línguas. Grosjean (2001), por sua vez, afirma que o bilinguismo está presente em alguns padrões, por exemplo, em contexto de fronteiras entre países onde há presença de duas línguas.

Entretanto, Zimmer, Finger e Scherer (2008) nos levam a entender que não existe uma definição exata para esse fenômeno, justamente por não haver consenso entre os seguintes questionamentos: "O que significa saber duas ou mais línguas?"; "Quanto um sujeito precisa saber da outra língua para ser classificado como sujeito bilíngue?". Conforme os mesmos autores, as respostas para essas indagações ocasionaram o pensamento de que o bilinguismo estaria ligado ao conhecimento de uma LE ou L2 não importando seu grau de proficiência.

Essas definições que concebem a língua como códigos distintos e separados, que necessitam ser adquiridos pelo sujeito bilíngue se aproximam do paradigma estruturalista, uma vez que as interpretações sobre bilinguismo estão relacionadas a conceitos tais quais proficiência, competência, desempenho, habilidade de distinguir e separar línguas, encontro/repertório linguístico, alternância entre duas línguas, entre outros. Em virtude disso, quando um sujeito bilíngue mistura as línguas durante a comunicação, fenômeno denominado por alternância de códigos, o qual compreende o "uso alternado de duas ou mais línguas na mesma fala" (GROSJEAN, 2001, p. 145, tradução nossa ${ }^{5}$ ), dentro do paradigma estruturalista, esse sujeito está manipulando simultaneamente dois códigos distintos, com palavras, sons e estruturas diferentes.

5 No original: "the alternate use of two or more languages in the same utterance or conversation" 
Em Picoli (2019), a visão de língua está intimamente ligada à concepção estruturalista, pois partiu do entendimento do sujeito bilíngue como aquele que tem habilidade em se comunicar em duas ou mais línguas (EDWARDS, 2006), mesmo que seja melhor em uma em relação à/às outra(s). Edwards (2006), baseando-se em Mackey (1968), cita algumas questões sobre as quais devemo-nos atentar ao definir o bilinguismo: o grau (proficiência), a função (fatores internos e externos ao sujeito), a interferência (gerenciamento das línguas) e o code-switching (alternância de códigos). Segundo o autor, o desempenho diferente em ambas será influenciado por alguns fatores como o contexto no qual o bilíngue está inserido, seu repertório linguístico, o propósito comunicativo, a classe social a qual pertence, a idade, o sexo, entre outros.

Em vista disso, acreditamos que a alternância de códigos merece destaque quando pensamos em aprendizagem de línguas na modalidade teletandem, visto que ela é um aspecto inerente a eventos discursivos bilíngues, cuja complexidade reside em questões próprias da língua (morfologia, sintaxe, semântica etc) e em fatores internos/externos (repertório linguístico/contexto social), que devem ser considerados em relação às motivações de uso linguístico dos sujeitos bilíngues.

Em relação às alternâncias de códigos, Grosjean (2001) esclarece que há alguns fatores presentes na escolha de uma língua em detrimento da outra, mas geralmente há uma combinação de muitos elementos. Por exemplo, um fator pode estar associado aos participantes, sendo a proficiência tanto desse falante quanto do(s) interlocutor(es) o traço mais importante. Outro fator pode estar associado à situação, por exemplo, ao local em que acontece a interação, à presença de monolíngues no local da interação etc. Pode estar relacionado também ao conteúdo da fala, pois há alguns assuntos que podem ser discutidos melhor em uma língua em relação à outra se os bilíngues aprenderem a lidar com esse assunto em uma língua particular. Finalmente, pode estar ligado à função da interação, na qual a intenção é o aumento de status, por exemplo, quando os bilíngues escolhem uma língua para excluir um monolíngue da interação. Independentemente do fator por trás da escolha da língua, há dois estágios no processo decisório para essa escolha: no primeiro estágio, o bilíngue decide qual língua utilizar e, no segundo, ele(a) opta pela alternância de código quando lhe convier (GROSJEAN, 2001).

Assim, neste estudo, a análise do princípio da igualdade foi conduzida por meio de duas perspectivas: a quantificação do tempo de prática para as duas línguas-alvo e a observação de eventos em que houve alternâncias de códigos. Antes de dar início à discussão e análise de dados, apresentaremos o contexto e os participantes desse estudo. 


\section{Contexto de pesquisa: participantes e instrumentos}

Os dados utilizados para o desenvolvimento da discussão proposta, neste artigo, são resultantes do acompanhamento das sessões de teletandem português e inglês, entre alunos da Universidade Estadual Paulista "Júlio de Mesquita Filho" (UNESP) e de duas universidades norte-americanas, no segundo semestre de 2017 (de setembro a outubro).

Participaram, desse estudo, três parcerias de teletandem formadas por brasileiros, cuja língua-materna é o português e que praticavam teletandem em inglês, na modalidade institucional não-integrada (praticam teletandem por interesse próprio) e estrangeiros, sendo dois deles norte-americanos, cujas línguas-maternas são o inglês e uma indiana que tem o hindi como língua materna, mas o inglês como língua de proficiência. Os estrangeiros praticavam teletandem em português, na modalidade institucional-integrada, ou seja, a prática da língua portuguesa com os brasileiros era parte obrigatória do currículo das suas respectivas universidades. O quadro, a seguir, ilustra as características dos participantes desse estudo, sendo PB os participantes brasileiros e PE os participantes estrangeiros, em cada um dos três grupos de interações.

Quadro 1. Características dos participantes da pesquisa

\begin{tabular}{|c|c|c|c|c|c|c|}
\hline & \multicolumn{6}{|c|}{ PARTICIPANTES DA PESQUISA } \\
\hline & PB1 & PE1 & PB2 & PE2 & PB3 & PE3 \\
\hline Nacionalidade & Brasileira & Estrangeira & Brasileiro & Estrangeiro & Brasileira & Estrangeiro \\
\hline$L M^{6} / L 2^{7}$ & Português & $\begin{array}{l}\text { LM: hindi } \\
\text { L2: inglês }\end{array}$ & Português & Inglês & Português & Inglês \\
\hline$L A^{8}$ & Inglês & Português & Inglês & Português & Inglês & Português \\
\hline $\begin{array}{l}\text { Conhecimento } \\
\text { na } L A\end{array}$ & Avançado & Iniciante & Intermediário & Intermediário & Iniciante & Iniciante \\
\hline Curso & $\begin{array}{l}\text { Pós- } \\
\text { graduação }\end{array}$ & Graduação & Graduação & Graduação & Graduação & $\begin{array}{l}\text { Pós- } \\
\text { graduação }\end{array}$ \\
\hline $\begin{array}{l}\text { Modalidade de } \\
\text { Teletandem }\end{array}$ & $\begin{array}{l}\text { Institucional } \\
\text { não- } \\
\text { integrado }\end{array}$ & $\begin{array}{l}\text { Institucional- } \\
\text { integrado }\end{array}$ & $\begin{array}{l}\text { Institucional } \\
\text { não-integrado }\end{array}$ & $\begin{array}{l}\text { Institucional- } \\
\text { integrado }\end{array}$ & $\begin{array}{l}\text { Institucional } \\
\text { não- } \\
\text { integrado }\end{array}$ & $\mid \begin{array}{l}\text { Institucional- } \\
\text { integrado }\end{array}$ \\
\hline
\end{tabular}

Fonte: Elaboração própria

\footnotetext{
6 Língua materna

7 Segunda língua

8 Língua-alvo
} 
Os instrumentos utilizados para a coleta de dados foram aplicação de questionário inicial aos participantes brasileiros, com o propósito de verificar suas expectativas em relação à prática de inglês no teletandem bem como compreender se e como dividiriam igualmente o tempo de prática para ambas as LAs; gravação das interações por meio do programa Evaer, aplicativo que grava as chamadas de áudio e vídeo do Skype; transcrições das interações e aplicação do questionário final, aos participantes brasileiros, a fim de verificar se suas expectativas relacionadas à prática de sua língua-alvo foram alcançadas bem como se praticaram alternâncias de códigos em algum momento da interação.

Para realizar nossa análise, que será exposta na próxima seção, consideramos como dados primários as transcrições das sessões de interação, que totalizaram quatro entre as parcerias PB1/PE1 e PB2/PE2 e duas entre a parceria PB3/PE3.

Realizamos nossa análise por meio da contagem de tempo dedicado à prática do português e do inglês durante as interações e da categorização das alternâncias de código durante a prática de ambas as línguas-alvo. É o que será demonstrado a seguir, na seção de análise e discussão dos dados.

\section{Análise e discussão dos dados}

Em relação ao cumprimento do princípio da igualdade, os participantes brasileiros responderam no questionário final que haviam dividido igualmente o tempo de prática para ambas as línguas. Dessa maneira, pudemos confirmar essa informação por meio da contabilização do tempo gasto para a prática do português e do inglês, através das gravações de áudio e vídeo das interações analisadas.

Após realizar essa quantificação, encontramos o seguinte resultado, sintetizado na Figura 1: 
Figura 1. Quantificação em tempo total de prática de cada língua nas três parcerias

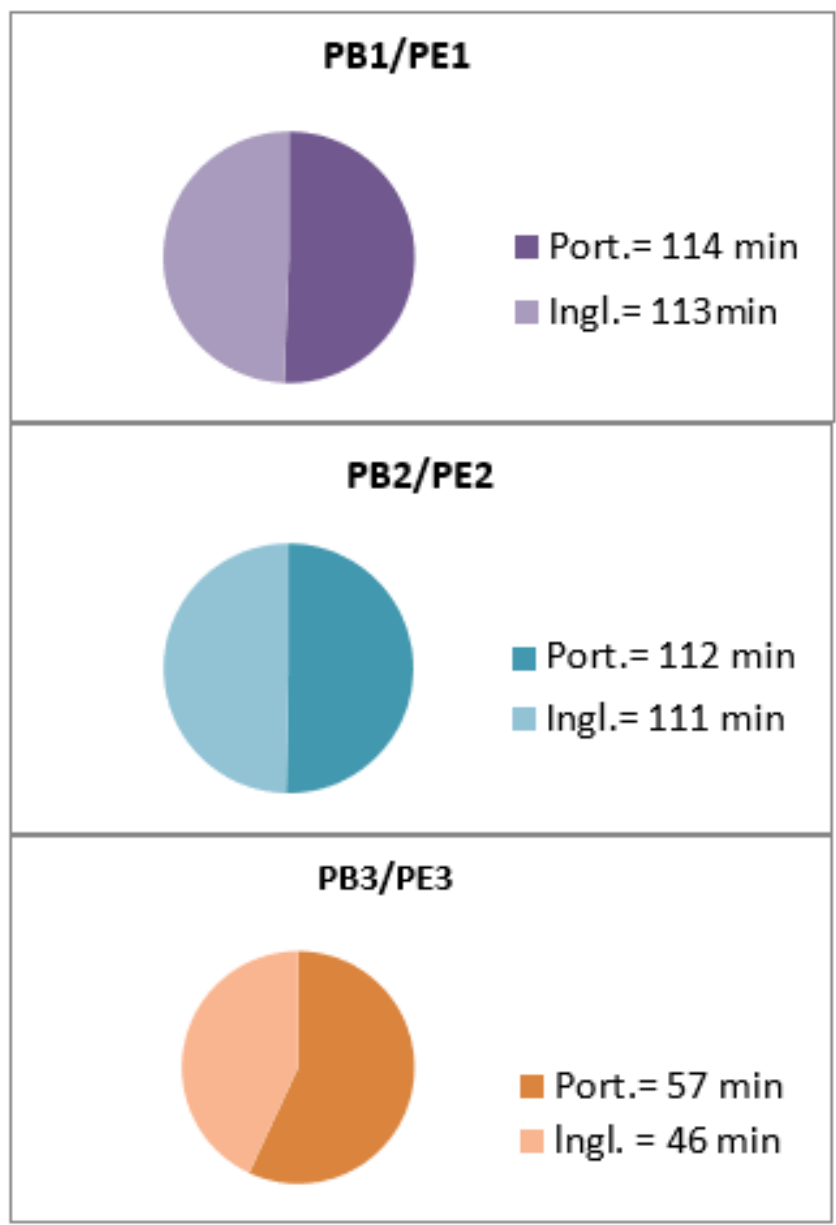

Fonte: Elaboração própria

Como observamos, nas parcerias 1 e 2 , os participantes praticamente realizaram o tempo de prática para ambas as línguas-alvo, cumprindo, na teoria, o princípio da igualdade. Contudo, a parceria 3 ultrapassou o tempo de prática do português em quase dez minutos, descumprindo parcialmente o princípio da igualdade, do ponto de vista do tempo dedicado à prática de ambas as línguas.

Por meio dos dados temporais, podemos concluir que as parcerias 1 e 2 podem ter se beneficiado de maneira equivalente na prática de suas línguas-alvo, enquanto, na parceria 3, a participante brasileira pode ter se beneficiado um pouco menos na prática do inglês, já que seu parceiro estrangeiro utilizou um tempo maior para a prática do português.

Posteriormente, ao perguntarmos aos participantes brasileiros, por meio do questionário final, se durante as sessões haviam misturado as línguas, eles responderam que haviam 
misturado em alguns momentos. Dessa maneira, ao analisarmos o cumprimento do princípio da igualdade do ponto de vista das alternâncias de códigos utilizando as gravações de áudio e vídeo das interações bem como o questionário final, encontramos um dado curioso: separar a mesma quantidade de tempo para a prática das línguas estrangeiras pode não significar que ambos os parceiros de teletandem se beneficiem, equitativamente, na prática de suas línguas-alvo, como verificaremos, a seguir, por meio dos gráficos da Figura 2:

Figura 2. Quantificação de alternâncias de código nas três parcerias

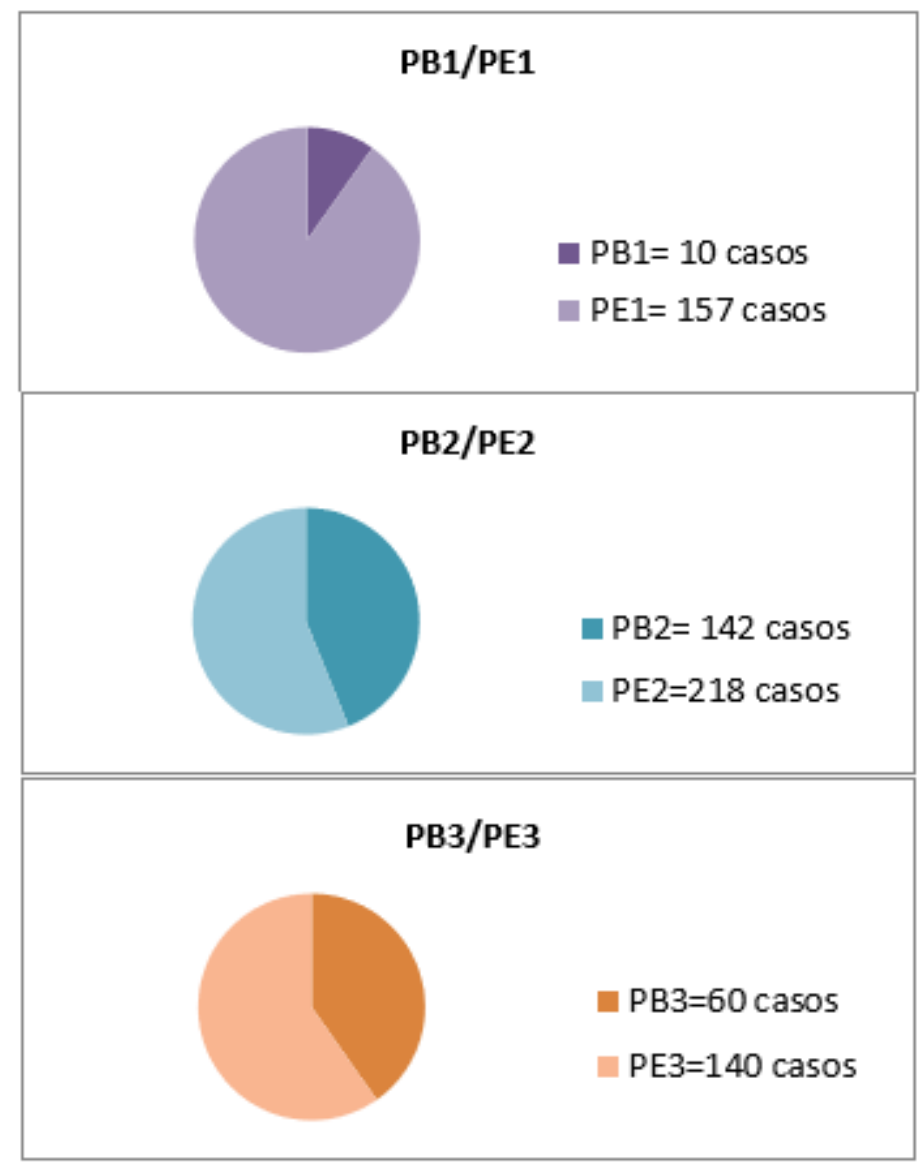

Fonte: Elaboração própria

Sob o aspecto da alternância de códigos, na parceria 1, observamos que a brasileira, PB1, utilizou bem menos esse recurso comparado à parceira, PE1. Portanto, ao alternar menos do inglês para outra língua, PB1 pode ter praticado mais sua língua-alvo do que PE1. Na parceria 2, o brasileiro, PB2, alternou menos do inglês para outra língua quando comparado ao seu parceiro, portanto, assim como PB1, PB2 pode ter se beneficiado mais na prática do inglês do que PE2 na prática do português. Finalmente, na parceria formada 
por PB3 e PE3, a brasileira também recorreu menos às alternâncias, quando praticava inglês, comparado ao seu parceiro ao praticar português. Assim, como os outros brasileiros, PB3 pode ter se beneficiado mais na prática do inglês do que seu parceiro (PE3) na prática do português.

Em relação à prática das alternâncias de códigos entre as três parcerias analisadas, observamos que as razões mais utilizadas foram acomodação, para expressar solidariedade, pedir esclarecimento e evitar prolongamento na fala utilizando a justaposição de duas ou mais línguas dentro do mesmo seguimento do diálogo, o qual denomina-se subordinação sequencial.

A fim de esclarecermos as razões mais acessadas para as alternâncias de códigos entre as parcerias, exemplificá-las-emos e destacá-las-emos nos trechos grifados em amarelo, por meio de pequenos excertos, como no fragmento, a seguir, extraído de uma interação entre PB1/PE1 em que a estrangeira utiliza a acomodação, empregando a palavra "programming" ao invés de "programação" para se referir ao seu curso de graduação:

\section{Acomodação}

\section{Excerto 1}

[01:12]]PE1]: Que você estudar?

[01:18][PB1]: O que eu estudo? Eu estudo ensino e aprendizado de línguas estrangeiras. E você?

[01:35][PE1]: Eu estudo informática e programming (Eu estudo informática e programação)

(Transcrição da interação entre PB1 e PE1 de 26 de setembro de 2017, via Skype)

Esse recurso também foi utilizado entre as parcerias PB2/PE2 e PB3/PE3, como maneira de resolver um problema relacionado à deficiência de vocabulário ou de esquecimento lexical, que pode comumente ocorrer durante a comunicação entre sujeitos bilíngues.

Em seguida, exemplificaremos um caso de solidariedade, encontrado em uma das interações entre PB2/PE2, que pode ser identificada através da tentativa do brasileiro em manter contato com seu parceiro através de rede social, das exclamações utilizadas pelo estrangeiro como forma de demonstrar empatia em relação ao seu parceiro e da forma branda de correção utilizada pelo participante brasileiro: 


\section{Solidariedade}

\section{Excerto 2}

[20:21][PB2]: Eu ia perguntar...você tem facebook?

[20:25][PE2]: Se tem que?

[20:25][PB2]: É facebook... facebook

[20:28][PE2]: Sí sí!!! Me agregas! (Sim, sim!!! Me adiciona)

\section{[20:31][PB2]: É aqui a gente fala adicionar}

[20:35][PE2]: Adicionar... Adicionar... [anota a escrita da palavra]

(Transcrição da interação entre PB2 e PE2 de 30 outubro de 2017, via Skype)

A solidariedade também esteve presente nas interações entre as parcerias PB1/PE1 e PB3/PE3 principalmente quando os parceiros tentaram manter contato através de redes sociais e nas formas de oferecer feedback corretivo de modo a não constranger o parceiro.

O esclarecimento é representado por meio de perguntas diretas, geralmente realizadas na língua materna ou de proficiência do sujeito bilíngue, durante a comunicação com seu(s) interlocutor(es), como observaremos a seguir, quando o estrangeiro pede para que a brasileira soletre seu nome para que ele possa anotar:

\section{Esclarecimento}

\section{Excerto 3}

\section{[06:04][PE3]: Como você escrebe? How do you spell it? (Como se soletra?)}

\section{[P.A5][PB3]: P-B-3!}

\section{(Transcrição da interação entre PB3 e PE3 de 23 de outubro de 2017, via Skype)}

Esse tipo de alternância foi recorrente nas interações entre as três parcerias, pois em alguns momentos os parceiros apresentaram dificuldade de permanecer se comunicando somente na língua-alvo. Assim, utilizando esse recurso, buscaram resolver dúvidas de vocabulário, expressões, sintaxe, entre outras, evitando a produção de falas muito extensas e como estratégia para dar continuidade à conversa.

Finalmente, a última motivação mais acessada para as alternâncias de códigos entre as parcerias foi a subordinação sequencial, que representa a dimensão de mais de um idioma dentro do mesmo seguimento da fala, como exposto, a seguir, quando PE3 inicia sua fala em português, alternando para o espanhol e em seguida para o inglês, para explicar à sua parceira (PB3) que os americanos não costumam conversar sobre aparências físicas: 


\section{Subordinação Sequencial}

\section{Excerto 4}

[22:02][PBE]: Do que vocês costumam conversar?

[22:04][PE3]: A... muitos tópicos pero no sobre su característica física... es una...es mais ou menos um insult to say like comment on somebody's like weight or their physical traits, is very strange in English... I don't know why... (... é mais ou menos um insulto comentar sobre o peso de alguém ou sobre características físicas, é muito estranho em inglês... eu não sei o porquê....)

[22:32][PB3]: Aqui a gente elogia bastante uns aos outros, então é mais comum [...] aqui é muito comum, em reuniões familiares [risos] falar sobre o peso... weight ${ }^{9}$...like li $^{10}$ "Oh my God how you are fat"!11...[risos de ambas as partes] is very common ${ }^{12 . . . . ~ e ́ ~ m a l ~}$ educado, impolite but is common ${ }^{13}$...

(Transcrição da interação entre PB3 e PE3 de 30 de outubro de 2017, via Skype)

Como visto, a subordinação sequencial representa a transição entre as línguas portuguesa, espanhola e inglesa dentro do mesmo seguimento da fala de PE3. De modo semelhante, isso ocorre na fala de PB3, que alterna do português para o inglês para dizer que é comum, para os brasileiros, conversarem sobre aparência física. Esse recurso parece ser utilizado para dar continuidade na conversa, evitar a produção de seguimentos de fala muito extensos e como forma de evitar mal-entendidos.

De maneira global, ao analisarmos os dados gerados por meio da quantificação de tempo para a prática das LEs, bem como os casos de alternâncias de códigos que ocorreram ao longo das interações, é possível concluir, primariamente, que:

(i) Dividir a mesma quantidade de tempo para a prática das línguas-alvo pode não garantir que ambos os parceiros de teletandem se beneficiem igualmente na prática de suas LEs;

(ii) Se houver uma constante prática de alternância de códigos pelos parceiros, durante as interações, pode ser que o princípio da igualdade seja quebrado uma vez que um dos parceiros pode não estar usando sua oportunidade de prática na língua-alvo.

\section{Peso.}

10 Por exemplo.

11 "Oh meu deus, você está gordo!".

12 É muito comum.

13 Mal-educado, mas comum. 
Porém, essas conclusões primárias podem nos lançar em um terreno perigoso, principalmente ao afirmar, implicitamente, que a constante prática de alternâncias de códigos prejudica o desenvolvimento da LE do participante que mais utilizar esse recurso. Ao retomarmos a definição de sujeito bilíngue elaborada por Edwards (2006), Romaine (1995) e Mackey (1968), a habilidade da comunicação bilíngue não pode ser medida pelo mesmo desempenho nas duas línguas, ou seja, as habilidades dos sujeitos bilíngues em ambas as línguas podem estar atreladas a níveis diferentes, por exemplo, um sujeito bilíngue pode ser proficiente nas habilidades de leitura e escrita, mas não tão proficiente na habilidade de compreensão e produção oral. De acordo com Romaine (1995), a proficiência e as competências na LE/L2 estão intimamente ligadas à quantidade de alternâncias envolvidas nas falas de sujeitos bilíngues, desse modo, a alternância de códigos desempenha uma importante função para o repertório comunicativo desses sujeitos.

Seguindo essa mesma linha de pensamento, Grosjean (2001), em sua obra Life with two languages, aponta que estudos sobre interlíngua têm analisado os erros dos aprendizes, concluindo que, ao adquirir uma segunda língua, o aprendiz passa por vários estágios ou sistemas linguísticos antes de adquirir o sistema do falante nativo. Esses estágios recebem o nome de interlíngua, que é resultante da tentativa do aprendiz de produção da língua-alvo. Assim, a aquisição ou não de fluência na segunda língua está relacionada às necessidades de comunicação, ou seja, se um bilíngue considerar que ele/ela conhece bem a língua para se comunicar, esse sujeito tende a fossilizar ${ }^{14}$ a L2 ou a LE.

Por outro lado, se o sujeito bilíngue tem o desejo de se integrar ao grupo de falantes proficientes da segunda língua, movidos pela motivação de inclusão nesse grupo, eles tendem a alcançar um nível muito maior de fluência quando comparados àqueles que fossilizaram a L2 ou a LE. Portanto, pensando sobre a perspectiva de bilinguismo defendida por Edwards (2006), Romaine (1995) e Mackey (1968) e de interlíngua, na análise de Grosjean (2001), ao confrontarmos essas teorias com os resultados da pesquisa, podemos concluir que:

(i) Em ambientes telecolaborativos, como é o caso do teletandem, pensar em separação de línguas é mover-se em direção a um paradigma monolíngue, ou seja, contrário ao que em realidade ocorre nas interações entre sujeitos bilíngues;

(ii) O princípio da separação de línguas assegura o mesmo tempo de prática para ambas as línguas-alvo, mas não certifica que ambos os parceiros se beneficiem igualmente na prática de suas LEs, justamente por haver diferentes concepções e motivações individuais sobre o quanto se deve avançar na língua-alvo;

14 Estacionar seu conhecimento na língua. 
(iii) A constante prática de alternância de códigos pelos parceiros, durante as interações, não parece ferir o princípio da igualdade/separação de línguas, se considerarmos que esse fenômeno faz parte do processo de interlíngua, isto é, que está relacionado às motivações individuais sobre quanto avançar ou não na L2 ou na LE e que dependem de fatores internos (razões particulares) e externos (contexto social, nível educacional etc.) ao sujeito bilíngue.

Portanto, ao discutirmos o princípio da igualdade/separação de línguas no teletandem, a ideia de usar as línguas em "proporções iguais" (SOUZA, 2006) e a importância em dedicarse a usar "somente uma língua" (VASSALLO; TELLES, 2009) durante cada parte da sessão pode nos levar à interpretação de que não devemos misturar as línguas em nenhum momento da interação, ou seja, que devemos evitar a prática de alternância de códigos, pois isso pode prejudicar o desenvolvimento na língua-alvo. Contudo, ao analisarmos os fenômenos decorrentes do bilinguismo (alternância de códigos), percebemos que alternar entre uma língua e outra é um recurso pertinente do próprio repertório bilíngue. Entendemos, assim, que o princípio da separação de línguas poderia ser denominado de princípio da igualdade (de oportunidades) para que incorpore o bilinguismo existente nesse contexto de forma includente, ou seja, reconhecendo o uso criativo e atrelado das duas línguas de acordo com as necessidades, objetivos e intenções dos falantes.

\section{Considerações finais}

Neste artigo, buscamos expor nossas considerações a respeito do funcionamento do princípio da separação de línguas dentro da perspectiva estruturalista, com o objetivo de discutir as teorias que o subjazem e analisar por meio de dados empíricos como ele funciona na prática, levando em consideração fenômenos resultantes das interações bilíngues, como a prática de alternância de códigos.

Pautamos nossas discussões nos pressupostos teóricos do Teletandem (TELLES; VASSALLO, 2006; VASSALLO; TELLES, 2006; 2009) e do bilinguismo (EDWARDS, 2006; GROSJEAN, 2001; HAUGEN, 1953; MACKEY, 1968; ROMAINE, 1995; WEINREICH, 1953; ZIMMER; FINGER; SCHERER, 2008), com o intuito de enfatizar a importância de se orientar por meio dessas teorias ao analisar o funcionamento da prática de línguas estrangeiras proporcionada por este contexto. Salientamos que o cumprimento do princípio da separação de línguas durante as sessões de teletandem parece não garantir que ambos os parceiros se beneficiem igualmente na prática de suas LAs, pois o avanço na LE depende tanto de motivações individuais, que estão relacionadas ao objetivo pessoal de aquisição da L2 ou da LE de cada aprendiz, quanto a fatores externos, como contexto social, nível educacional dos aprendizes, entre outros.

Dentro da concepção estruturalista de língua, os dados empíricos demonstram também que há diferentes motivações para a alternância de códigos, que vão desde a solução 
de problemas relacionados à deficiência de vocabulário até como recurso para dar continuidade à conversa, evitar a produção de seguimentos de fala muito extensos e como forma de evitar mal-entendidos, ou seja, ela é geralmente utilizada como estratégia de compensação pelos aprendizes Desse modo, acreditamos que futuros estudos poderão contribuir para avançar na análise deste princípio a partir de uma perspectiva cuja noção de língua seja respaldada em uma concepção dinâmica, construída socialmente, na qual os bilíngues sejam caracterizados pelas suas práticas discursivas múltiplas, cuja finalidade é a construção de sentido em seus contextos sócio-históricos.

Por fim, em relação ao cumprimento do princípio da separação de línguas, pensar que o bilíngue deve separar completamente o uso das duas línguas que conhece parece ser uma idealização teórica que se respalda em um paradigma monolíngue, e não na ideia de que os conhecimentos linguísticos dos falantes bilíngues estão em contato e se influenciam mutuamente. Assim, propomos que ele seja denominado de princípio da igualdade (de oportunidade de prática da LE), como intitulado por Panichi (2002), e que futuras definições para ele na prática de línguas em teletandem levem em consideração que o avanço do desenvolvimento na língua-alvo pode depender, em parte, da divisão temporal para a prática das LEs, mas também está relacionado aos objetivos, expectativas e recursos linguísticos dos aprendizes.

\section{REFERÊNCIAS}

BENEDETTI, A. M. Pesquisas em ensino e aprendizagem no teletandem Brasil: línguas estrangeiras para todos. In: TELLES, J. A. (org.). Teletandem: um contexto virtual, autônomo e colaborativo para a aprendizagem de línguas estrangeiras no século XXI. Campinas: Pontes, 2009.

BRAMMERTS, H. Aprendizagem autónoma de línguas em tandem: desenvolvimento de um conceito. In: DELILLE, K. H.; CHICHORRO, A. (org.). Aprendizagem autónoma de línguas em tandem. Coimbra: Edições Colibri, 2002.

CALVERT, M. Tandem: a vehicle for language and intercultural learning. Language Learning Journal, v. 19, p. 56-60, 1999.

COSTA, L. M. G.; SALOMÃO, A. C. B.; ZAKIR, M. A. Transcultural and Transcontinental Telecollaboration for Foreign Language Learning: proposals and challenges. Revista do GEL, v. 15, n. 3, p. 26-41, 2018.

EDWARDS, J. Foundations of Bilingualism. In: BHATIA, T. K. et al. (org.). The Handbook of Bilingualism. Oxford: Blackwell, 2006. p. 7-31. 
GARCÍA, O.; WEI, L. Translanguaging: Languaging, Bilingualism and Education. The Graduate Center, City University of New York, USA and Birkbeck College, University of London, UK: Palgrave Macmillan, 2014.

GROSJEAN, F. Life with Two Languages: An Introduction to Bilingualism. Cambridge, Massachusetts, London and England: Harvard University Press, 2001.

HAUGEN, E. The Norwegian language in America: A study of bilingual behavior. Philadelphia: University of Pennsylvania Press, 1953.

LITTLE, D. A aprendizagem de línguas em tandem e a autonomia do aprendente. In: DELILLE, K. H.; CHICHORRO, A. (org.). Aprendizagem autónoma de línguas em tandem. Coimbra: Edições Colibri, 2002.

MACKEY, W. F. The description of bilingualism. New York: Fishman editor, 1968.

PANICHI, L. Tandem learning and language awareness. Materials from ALA Tandem Workshop. Presented at the Sixth International Conference of the Association for Language Awareness: ALA 2002 (Umeå Universitet, Umeå, Sweden)[ não paginado].

PICOLI, F. Projeto Teletandem Brasil: um estudo do princípio da igualdade nas interações sob a ótica das alternâncias de códigos. 2019. Dissertação (Mestrado em Linguística e Língua Portuguesa) - Faculdade de Ciências e Letras, Universidade Estadual Paulista "Júlio de Mesquita Filho", Araraquara, 2019. Disponível em: https://repositorio.unesp.br/ handle/11449/182384. Acesso em: 04 out. 2020.

ROMAINE, S. Bilingualism. 2nd edition. Merton College, University of Oxford, 1995.

SALOMÃO, A. C. B.; SILVA, A. C.; DANIEL, F. de G. A aprendizagem colaborativa em Tandem: um olhar sobre seus princípios. In: TELLES, J. A. (org.). Teletandem: um contexto virtual, autônomo e colaborativo para aprendizagem de línguas estrangeiras no século XXI. Campinas: Pontes, 2009. p. 75-92.

TELLES, J. A. Teletandem: um contexto virtual, autônomo e colaborativo para aprendizagem de línguas estrangeiras no século XXI. Campinas: Pontes, 2009. 
TELLES, J. A.; VASSALLO, M. L. Foreign Language Learning In-tandem: Teletandem as an Alternative Proposal in CALLT. Aprendizagem de Línguas In-tandem: Teletandem Como uma proposta alternativa em CALLT. The Especialist, n. 2, v. 27, p. 189-212, 2006. Disponível em: http://citeseerx.ist.psu.edu/viewdoc/ download?doi=10.1.1.1025.2815\&rep=rep1\&type=pdf. Acesso em: 03 out. 2020.

VASSALLO, M. L.; TELLES, J. A. Ensino e aprendizagem de línguas em tandem: princípios teóricos e perspectivas de pesquisa. In: TELLES, J. A. (org.). Teletandem: um contexto virtual, autônomo e colaborativo para a aprendizagem de línguas estrangeiras no século XXI. Campinas: Pontes, 2009.

VASSALLO, M. L.; TELLES, J. A. Foreign language learning in-tandem:

Theoretical principles and research perspectives. The ESPecialist, n. 1, v. 27, p. 83-118, 2006. Disponível em: http://citeseerx.ist.psu.edu/viewdoc/ download?doi=10.1.1.845.2443\&rep=rep1\&type=pdf. Acesso em: 28 jan. 2019.

WEINREICH, U. Languages in Contact. New York: Linguistics Circle of New York, 1953.

ZIMMER, M. C.; FINGER, I.; SCHERER, L. Do Bilinguismo ao Multilinguismo: Intersecções entre a Psicolinguística e a Neurolinguística. Revel, n. 11, v. 6, ago. 2008. 